\title{
CESAREAN DELIVERY; TO EVALUATE THE GASTRO INTESTINAL EFFECTS WITH EARLY FEEDING ARE BETTER THAN DELAYED FEEDING pushpa.saroop@yahoo.com
}

\author{
1. MBBS (FCPS) \\ Registrar \\ CDF Hospital Hyderabad \\ 2. MBBS, FCPS \\ Senior Instructor \\ Aga Secondary Hospital \\ Hyderabad \\ 3. MBBS, FCPS \\ Registrar \\ CDF Hospital Hyderabad
}

Correspondence Address: Dr. Pushpa Chetandas

MBBS, FCPS, MS

Aga Secondary Hospital Hyderabad

pushpa.saroop@yahoo.com

Article received on:

17/03/2016

Accepted for publication:

16/07/2016

Received after proof reading:

$10 / 09 / 2016$

\section{Dr. Meshwari Beesham¹, Dr. Pushpa Chetandas², Dr. Neeta Sham ${ }^{3}$}

\begin{abstract}
In obstetrics, the rate of caesarean section has consistently expanded globally. Generally, after caesarean section the solid food has been stopped to women for $1^{\text {st }} 24$ hours so that it could avoid gastro intestinal complications. Mostly in all the cesarean section cases was operated by regional anesthesia where in little intestinal manipulation and short operative time. The aim of this study is to know that the gastrointestinal effect on early feeding versus delayed feeding after uncomplicated cesarean section and the better practice as well as advocated in future. Objective: Evaluation of the gastro intestinal effects with early feeding is better than delayed feeding after cesarean delivery. Study Design: Randomized controlled clinical trial. Setting: Obstetrics \& Gynaecological Department, Liaquat University Hospital, and Hyderabad. Period: January 2012 to January 2013. Methodology: A total number of 352 women uncomplicated emergency or elective cesarean section under spinal anesthesia was included in this study. Consenting women were randomly assigned into two groups such as early feeding group and delayed feeding group. Any complaint about anorexia, nausea, vomiting, abdominal discomfort and abdominal distention on physical examination was noted. Results: Rate of ileus, anorexia was significantly low in early feeding groups as compare to delayed feeding group while rate of vomiting and abdominal distension were not significant between groups. Average time of first bowel sound and time of passage of flatus and passage of stool were significant between groups. Conclusion: In conclusion, early feeding fastens the recovery and lowers complication rate.
\end{abstract}

Key words: $\quad$ Gastro intestinal complication, Cesarean delivery, spinal anesthesia, ileus, anorexia.

Article Citation: Beesham M, Chetanas P, Sham N. Cesarean delivery; to evaluate the gastro intestinal effects with early feeding are better than delayed feeding. Professional Med J 2016;23(9):1026-1032. DOI: 10.17957/TPMJ/16.3361

\section{INTRODUCTION}

In obstetrics, the rate of caesarean section has consistently expanded globally in last few years. The prevalence rate of different countries in cesarean section i.e. USA (29.1\%), England (21.5\%) and Latin America (40\%). ${ }^{1}$ Generally, after caesarean section the solid food has been stopped to women for $1^{\text {st }} 24$ hours so that it could avoid gastro intestinal complications. In previous studies, different systemic review and controlled trials have proven that early feeding is as safe as traditional progressive approach. ${ }^{2}$ Mostly in all the cesarean section cases was operated by regional anesthesia requiring little intestinal manipulation as well as short operative time. Another study have not shown any complications after caesarean section in early feeding but another advantages evaluated i.e. decreased hospital stay and early ambulation. $^{3}$

In addition, the early feeding in recent studies have indicated that it may decrease the exhausting protein store, early recovery and discharge from hospital. ${ }^{4}$ It was recommended that all selected cases discharge from the hospital after the caesarean birth as a safe, practicable, effectual choice and reasonable. In other comparative study, the early suggestion of ileus before operation with complication of gastro intestinal rates after early oral feeding and delayed feeding under cesarean section. ${ }^{5}$ Several other studies have indicated about early oral intake is safe even after bowel resection surgery. ${ }^{6}$ Teoh et al has proved in his randomized trial study that no difference in mild ileus symptoms (3.1\%). Postoperatively, the bowel sounds were analyzed 
in early group $90 \%$ and as compare to control group $90.5 \%$. Earlier passage of flatus (in hours) $14.4 \pm 9.4$ versus $21.0 \pm 18.2$, first stool (in hours) $44.4+18$ versus $65.6 \pm 25.4$ and discharge Earlier (in hours) $44.3 \pm 10.4$ versus $62.0 \pm 12.7$ were found. ${ }^{7}$ Chantarasorn $\mathrm{V}$ et al in this randomized trial study, the early oral feeding as compare to delayed feeding were analyzed that the early feeding in ileus symptoms (mild) was considered less than conventional group significantly i.e. $19.6 \%$ versus $31.1 \%(p=0.03) .^{3}$ The purpose of my study is to know Gastro intestinal effect on early versus delayed feeding after uncomplicated cesarean section and the better of the two will be practice and advocated in future.

\section{MATERIAL AND METHODS}

The Randomized controlled clinical trial was conducted at Obstetrics \& Gynaecological Department, Liaquat University Hospital, Hyderabad from January 2012 to January 2013. After fulfilling the inclusion criteria, all the selected women were informed about this study. Ethical permission was taken from ethical committee at LUMHS after approval of synopsis. Informed consent was taken from every participant. Demographics information was collected including patient's age, parity, gestational age \& indication of cesarean section. Samples were randomized by using computer generated random sequence. Allocation concealment was achieved by placing the allocation in sequentially numbered opaque sealed envelope. Time of start of cesarean section and total duration of cesarean section was noted.

Consenting women were randomly assigned to one of two groups.

1. Early feeding group was offered liquid diet 4 hours after the cesarean section followed by solid diet 6 hours after the cesarean section.

2. Delayed feeding group was offered oral fluid 12 hours after the cesarean section followed by solid diet after 18 hours.

Both groups were examined by hospital staff, House officers \& Gynaecology and Obstetrics resident (1-4 years) twice a day to assess the outcome variable. Any complaint about anorexia, nausea, vomiting, abdominal discomfort and abdominal distention on physical examination was noted. Other variable evaluated as post operative time interval to presence of bowel sounds, passage of flatus \& stool was recorded in hours. The data was analyzed using SPSS version 10.0. A comparative descriptive analysis of continuous \& categorical variables was performed. Chisquare test was applied to compare the incidence of ileus between two groups. Stratification was done with regards to age, gestational age, parity to see the effect on outcome. P-value of $<0.05$ will be considered as significant.

\section{RESULTS}

A total of 352 women uncomplicated emergency or elective cesarean section under spinal anesthesia was included in this study. Patients were randomly assigned to one of two groups. 176 Patients in early feeding group was offered liquid diet 4 hours after the cesarean section followed by solid diet 6 hours after the cesarean section and 176 patients in delayed feeding group was offered oral fluid 12 hours after the cesarean section followed by solid diet after 18 hours. Age distribution of the cases is presented in Figure- 1 . Average age of the women in early feeding was $28.38 \pm 5.68$ years and delayed feeding was $27.60 \pm 4.88$ years, similarly average gestational age and duration of surgery is also presented in Table-l. Distribution of gestational age of the women is shown in Figure-2. Regarding parity, $28(8 \%)$ women had nulliparous $97(27.6 \%)$ had primipara, 204(58\%) had multipara and 23(6.5\%) had grand multipara. Parity status with respect to groups is as shown in Table-II. Comparison of gastro intestinal symptoms and ileus between groups is presented in Table-III. Rate of ileus, anorexia was significantly low in early feeding groups as compare to delayed feeding group while rate of vomiting was also low in early feeding but statistically significant difference was not observed $(p=0.19)$. Rate of abdominal distension was also not significant between groups $(p=0.77)$. 


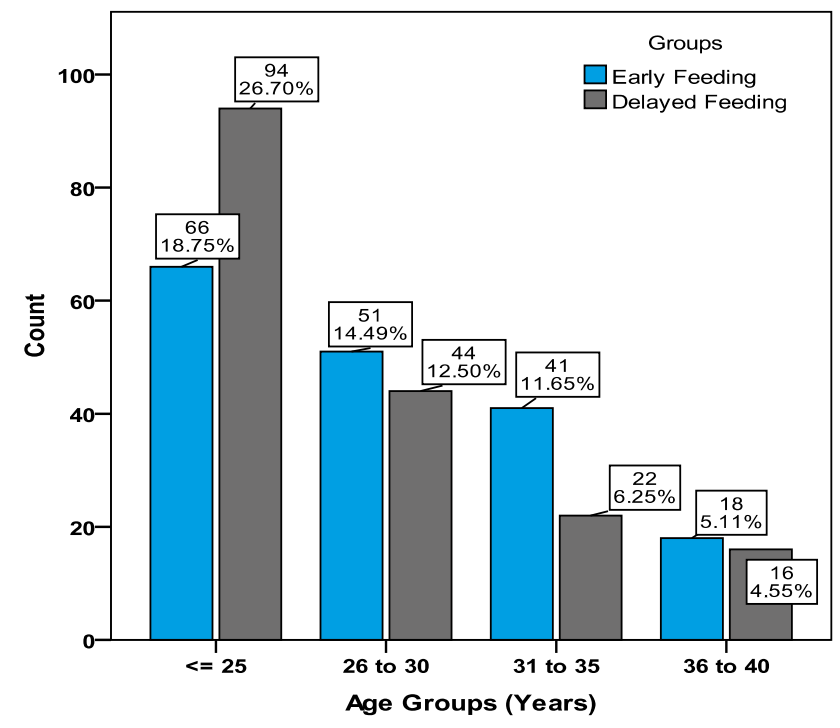

Figure-1. Age distribution $(n=352)$

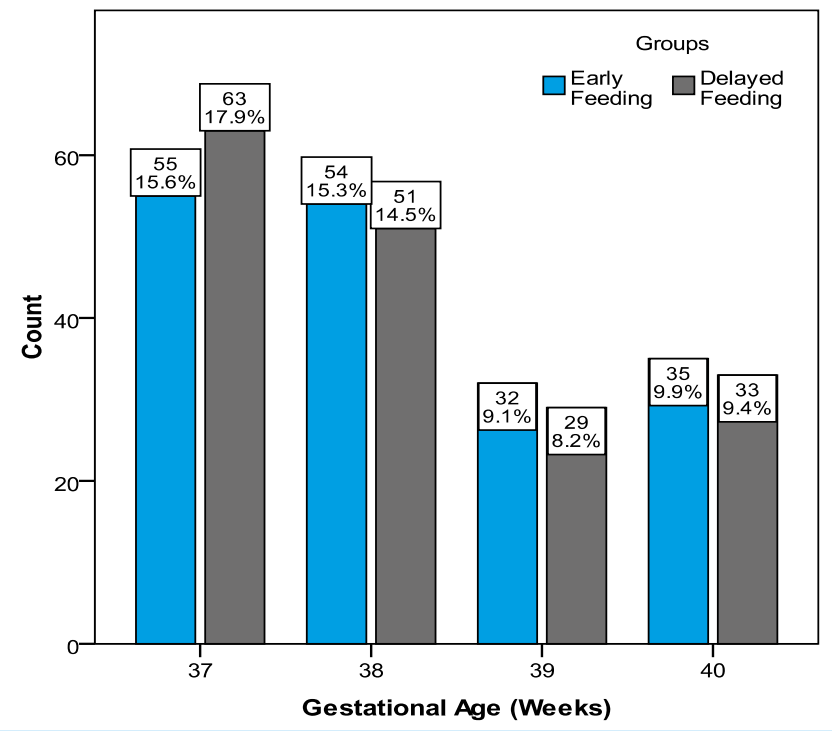

Figure-2. Gestational age $(n=352)$

\begin{tabular}{|l|c|c|c|}
\hline Parity (number of children) & Early Feeding $\mathbf{n = 1 7 6}$ & Delayed Feeding $\mathbf{n = 1 7 6}$ & Total \\
\hline Nullipara (0) & $10(5.7 \%)$ & $18(10.2 \%)$ & 28(8\%) \\
\hline Primipara (1) & $45(25.6 \%)$ & $52(29.5 \%)$ & $97(27.6 \%)$ \\
\hline Multipara (2 to 5) & $101(57.4 \%)$ & $103(58.5 \%)$ & $204(58 \%)$ \\
\hline Grand Multipara (>5) & $20(11.4 \%)$ & $3(1.7 \%)$ & $23(6.5 \%)$ \\
\hline
\end{tabular}

\begin{tabular}{|l|c|c|c|}
\hline Gastro Intestinal Symptoms and Ileus & Early Feeding $\mathbf{n = 1 7 6}$ & Delayed Feeding $\mathbf{n = 1 7 6}$ & P-Values \\
\hline Ileus & $\mathbf{7 ( 4 \% )}$ & $19(10.8 \%)$ & 0.014 \\
\hline Anorexia & $30(17 \%)$ & $48(27.3 \%)$ & 0.021 \\
\hline Vomiting & $25(14.2 \%)$ & $34(19.3 \%)$ & 0.19 \\
\hline Abdominal Distension & $31(17.6 \%)$ & $29(16.5 \%)$ & 0.77 \\
\hline
\end{tabular}

Table-II. Comparison of gastrointestinal effect between groups

Chi-Square test

\begin{tabular}{|l|c|c|c|}
\hline Gastro Intestinal Symptoms and Ileus & Early Feeding $\mathbf{n = 1 0 9}$ & Delayed Feeding $\mathbf{n = 1 1 4}$ & P-Values \\
\hline Ileus & $4(3.7 \%)$ & $11(9.6 \%)$ & 0.075 \\
\hline Anorexia & $20(18.3 \%)$ & $30(26.3 \%)$ & 0.15 \\
\hline Vomiting & $14(12.8 \%)$ & $24(21.1 \%)$ & 0.10 \\
\hline Abdominal distension & $14(12.8 \%)$ & $18(15.8 \%)$ & 0.53 \\
\hline
\end{tabular}

Table-III. Comparison of gastro intestinal symptoms and Ileus for Gestational age 37 to 38 Weeks Chi-Square test

Average time of first bowel sound was also significant between groups $(13.75 \pm 3.83$ hours vs. $16.74 \pm 4.16$ hours; $p=0.0005$ ) as shown in Figure-3. Similarly average time of passage of flatus and passage of stool were also significantly low in early feeding groups than delayed feeding group (19.36 \pm 5.71 hours vs. $23.89 \pm 7.46$ hours $\mathrm{p}=0.0005)$ shown in Figure-4 and $(36.15 \pm 9.77$ hours vs. 44.51 $\pm 8.72 ; p=0.0005)$ shown in Figure-5 respectively. 


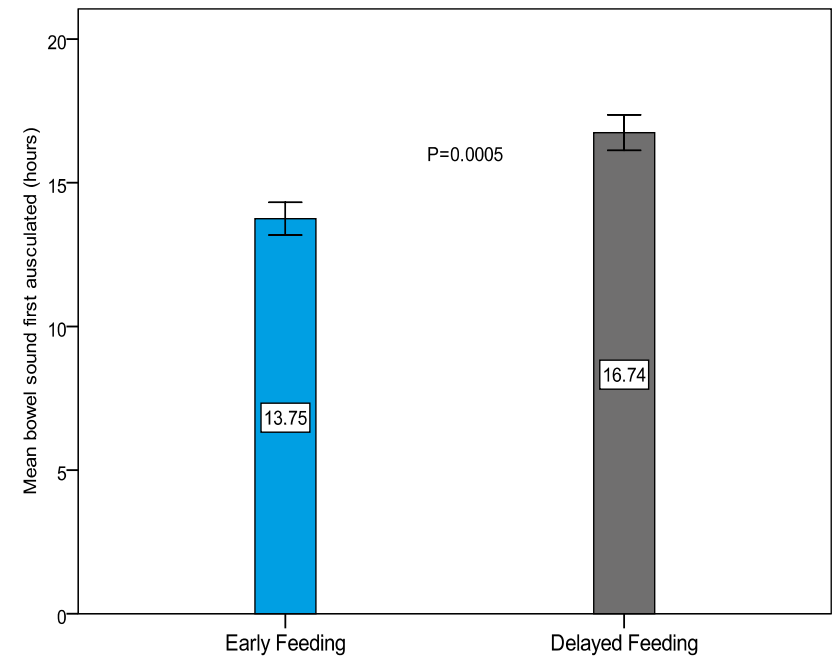

Figure-3. Comparison of mean bowel sound first ausculated $(n=352)$

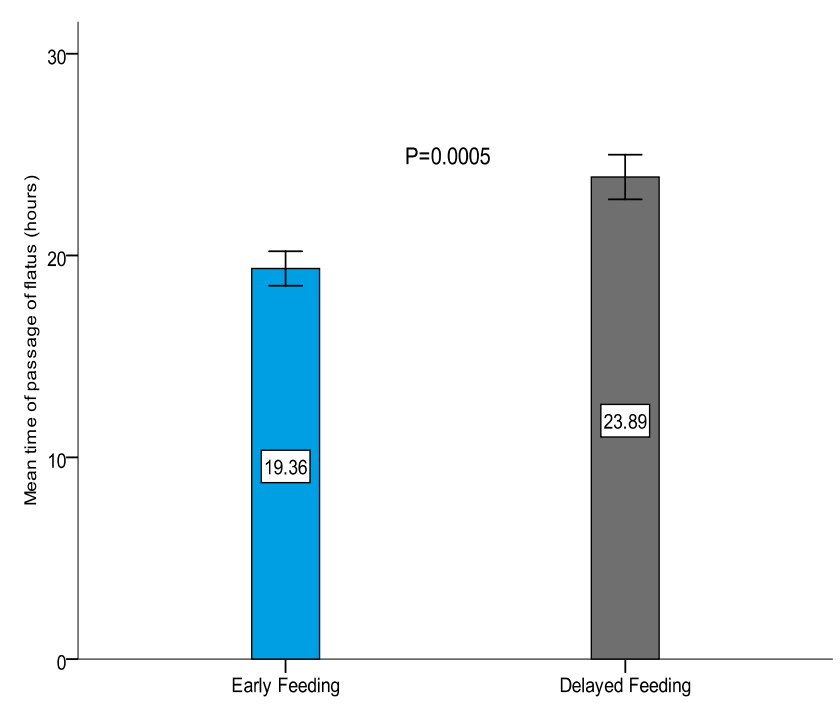

Figure-4. Comparison of mean time of passage of flatus $(n=352)$

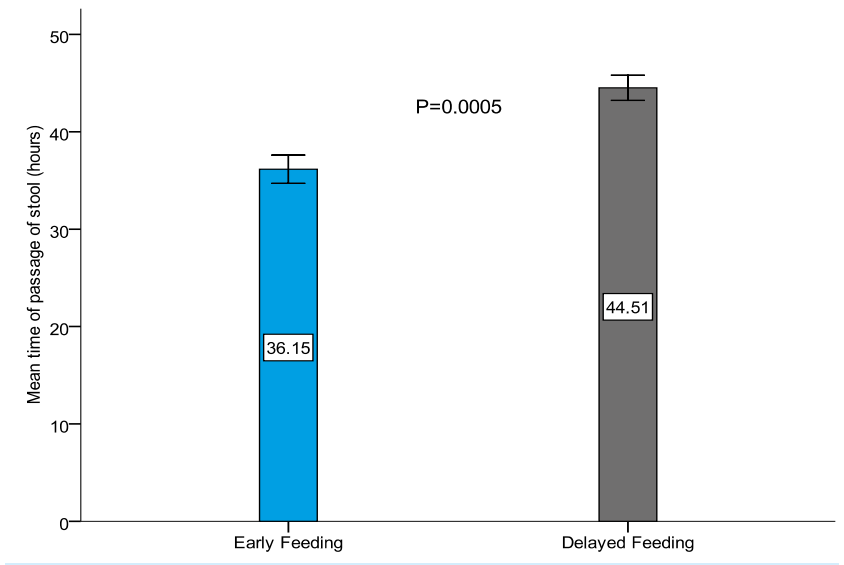

Figure-5. Comparison of mean time of passage of flatus $(n=352)$

Stratification analysis was performed with respect to age, rate of ileus, anorexia, vomiting were significantly low in early feeding groups as compare to delayed feeding group for below and equal to 30 years of age (Table-IV). Similarly average time of first bowel sound, time of passage of flatus and stool was also significant between groups as presented in Table-V, while rate of ileus, anorexia, abdominal distension was not significant between groups only rate of vomiting was significantly low in early feeding groups as compare to delayed feeding group for above 30 years of age (Table-IV) Similarly average time of first bowel sound, time of passage of flatus and stool was also significant between groups as presented in Table-V. Outcome was also observed with respect to gestational age and parity of the women and presented in 8 to 15.

\begin{tabular}{|l|c|c|}
\hline \multicolumn{1}{|c|}{ Variables } & $\begin{array}{c}\text { Early Feeding } \\
\mathbf{n = 1 0 9}\end{array}$ & $\begin{array}{c}\text { Delayed Feeding } \\
\mathbf{n = 1 1 4}\end{array}$ \\
\hline Time of first bowel sound (hrs) & $14.00 \pm 4.0$ & $16.74 \pm 4.44$ \\
\hline Time of passage of flatus (hrs) & $19.51 \pm 6.17$ & $24.14 \pm 6.58$ \\
\hline Time of passage of stool (hrs) & $36.58 \pm 9.34$ & $45.56 \pm 8.83$ \\
\hline Table-IV. Comparison of time related characteristics between groups for gestational age 37 to 38 Weeks \\
\hline
\end{tabular}




\begin{tabular}{|c|c|c|c|}
\hline GASTRO INTESTINAL Symptoms and Ileus & $\begin{array}{l}\text { Early Feeding } \\
\quad \mathrm{n}=67\end{array}$ & $\begin{array}{l}\text { Delayed Feeding } \\
\quad \mathrm{n}=62\end{array}$ & P-Values \\
\hline Ileus & $3(4.5 \%)$ & $8(12.9 \%)$ & 0.08 \\
\hline Anorexia & $10(14.9 \%)$ & $18(29 \%)$ & 0.52 \\
\hline Vomiting & $11(16.4 \%)$ & $10(16.1 \%)$ & 0.95 \\
\hline Abdominal distension & $17(25.4 \%)$ & $11(17.7 \%)$ & 0.29 \\
\hline \multicolumn{4}{|c|}{$\begin{array}{c}\text { Table-V. Comparison of gastro intestinal symptoms and ileus between groups for gestational age } 39 \text { to } 40 \text { week } \\
\text { Chi-Square test }\end{array}$} \\
\hline Gastro Intestinal Symptoms and Ileus & $\begin{array}{l}\text { Early Feeding } \\
\qquad \mathrm{n}=121\end{array}$ & $\begin{array}{l}\text { Delayed Feeding } \\
\quad n=108\end{array}$ & P-Values \\
\hline lleus & $7(5.8 \%)$ & $13(12 \%)$ & 0.09 \\
\hline Anorexia & $26(21.5 \%)$ & $36(33.3 \%)$ & 0.04 \\
\hline Vomiting & $14(11.6 \%)$ & $14(13 \%)$ & 0.74 \\
\hline Abdominal distension & $28(23.1 \%)$ & $23(21.3 \%)$ & 0.73 \\
\hline
\end{tabular}

\section{DISCUSSION}

Many of the studies have stated that the early oral feeding after laparotomy and caesarean birth is in a satisfactory manner or good health and agreeable for patients. ${ }^{8,9}$ While It compared that some women were not given solid food under 12 hours after cesarean birth, that women was not injected pain killers. ${ }^{8}$ About all the researchers have investigated the early solid food may be accepted by the women after cesarean birth and proved no any side effects erupted during the hospital stay. ${ }^{10}$

Many comparative studies of early and delayed feeding after cesarean birth have been published. ${ }^{11}$ This was compared beginning time of feeding after quick surgery between groups that in early oral feeding found 8 hours and delayed feeding 12 to 24 hours. In this previous study, women were given liquid diet for four hours (early feeding) and solid food were given to women for six hour after cesarean birth as a consequence of complications was present hemorrhage during the study. There were no significant differences in bowel complications between early and delayed feeding groups. ${ }^{9,10}$

Uncomplicated emergency or elective cesarean section under spinal anesthesia was included in this study. In present study women in both groups had similar demographic characteristics; including age, parity and gestational age. According to Chantarasorn $\mathrm{V}$ et $\mathrm{al}^{3}$ and Kovavisarach et $\mathrm{al}^{10}$ also reported same results. Both were proved that no any significant differences in the demographic data between the two groups.

In this study, women in the early feeding group had fewer ileus symptoms when compared with the conventional feeding group. Rate of ileus, anorexia was significantly low in early feeding groups when compare to delayed feeding group while rate of vomiting was also low in early feeding but statistically significant difference was not observed $(p=0.19)$. Rate of abdominal distension was also not significant between groups $(p=0.77)$. This might be the result of early ambulation, as the patient had to get up within 6 hours after surgery to start a solid diet.

When the early oral feeding were given that the bowel function also recovered in short term after procedure to the first active bowel movement which was same consequences found in another study. ${ }^{8,10}$ This might be the positive effect on the gastrointestinal tract, where such stimulation may decrease the length of postoperative ileus.

In this study average time of first bowel sound was also significant between groups (in hours) 
$13.75 \pm 3.83$ versus $16.74 \pm 4.16$ ( $p$-value $=0.0005)$. Similarly average time of passage of flatus and passage of stool were also significantly low in early feeding groups than delayed feeding group (in hours) $19.36 \pm 5.71$ versus $23.89 \pm 7.46$ (p. value $=0.0005$ ) and $36.15 \pm 9.77$ versus $44.51 \pm 8.72$ (p. value $=0.0005)$.

Teoh et al showed using randomized trial study that there is no difference in mild ileus symptoms (3.1\%). After the immediate procedure, the bowel sounds had in $90 \%$ (Early group) versus $90.5 \%$ (control). In addition earlier passage of flatus (in hours) $14.4 \pm 9.4$ versus $21.0 \pm 18.2$, first stool (in hours) $44.4+18$ versus $65.6+25.4$ and discharge earlier (in hours) $44.3 \pm 10.4$ versus $62.0 \pm 12.7$ were found. ${ }^{7}$ In another randomized trial of early versus delayed feeding by Chantarsorn et al showed that it was low significant rate $19.6 \%$ in early oral feeding versus conventional group $31.1 \%$ and $p$-value was $0.03 .^{3}$

The early oral feeding has been advocated for both its nutritional value and positive effects on the bowel, where such stimulation may help to decrease the duration of postoperative ileus. ${ }^{12}$

In this present study have a limitation that nutritional instructions were given to women but actual amount of food eaten was not quantified by the use of a food diary. It is fact that the patients and doctors have knowledge about feeding practice of this type of intervention but may be effected the mentioned complications (nausea \& abdominal cramping). In addition to recurrent rate of bowel function recognized due to the passage of flatus and in most studies was limiting factor for discharge.

\section{CONCLUSION}

In conclusion, after successful caesarean section may be reduced all symptoms of gastro intestinal and complication rate in early oral feeding and it was found that the early oral feeding is a safe, fastens recovery and good health. In addition to other benefits of the early oral feeding are less hospital stay, hospital cost and after the procedure, women need not to be tolerated of hunger and thirst.

Copyright (C) 16 July, 2016.

\section{REFERENCES}

1. Nizam K, Haider, Memon N, Haider A. Cesarean Section rate: much room for reduction. Rawal Med J. 2010; 35:19-22.

2. Izbzky G, Mining L, Sebastian M. The effect of early versus delayed post cesarean feeding on women's satisfaction: a randomized controlled trail. BJOG. 2008; 115:332-8.

3. Chantarasorn V, Tannirandorn V. A comparative study of early post operative feeding vesusconvetional feeding for patients undergoing cesarean section, A randomized controlled trail. J Med Assoc Thai. 2006; 89:511-5.

4. Adupa D, Wandabwa J, KoindoP. A randomized controlled tail of ealy initiation of oral feeding after cesarean delivery in mulago hospital east. African Med J. 2003; 80:345-50.

5. Abd-El-Maebound K, Ibrahim M, Shalaby D, Fikry M. Gum Chewing stimulates early return of bowel motility after caesarean section. BJOG. 2009; 116:1334-9.

6. Andrew J, Sarah S. Fast track surgery and anesthesia continuing education in anesthesia, critical care and pain. Oxford J.2009; 9(2):39-43.

7. Teoh WHL, Shah MK, Mah $\mathrm{Cl}$. A randomized controlled trial on beneficial effects of early feeding post cesarean delivery under regional anesthesia. Singapore Med J. 2007; 48(2); 152-7.

8. 102Soriano D, Dulitzki M, Keidar N, Barkai G, Mashiach S, Seidman DS. Early oral feeding after cesarean delivery. Obstet Gynecol. 1996; 87: 1006-8.

9. 103Patolia DS, Hilliard RL, Toy EC, Baker B. Early feeding after cesarean: randomized trial. Obstet Gynecol. 2001; 98: 113-6.

10. 104Kovavisarach E, Atthakorn M. Early versus delayed oral feeding after cesarean delivery. Int $\mathrm{J}$ Gynecol Obstet. 2005; 90: 31-4.

11. Virojchaiwong $P$, Benrahm $D$. The gastrointestinal complication after early oral feeding in term elective cesarean delivery. Vajira Med J. 2001; 44:27- 35.

12. Bowling TE. Does disorder of gastrointestinal motility after food intake in the post-surgical patient? Proc Nutr Soc. $1994 ; 53: 151-7$. 


\section{PREVIOUS RELATED STUDY}

Bushra Sher Zaman, Rashad Qamar, Sumera Siddique, Ali Zulqarnain, Anza Saleem. VAGINAL DELIVERY VERSUS CESAREAN SECTION; BIRTH OUTCOME IN PRIMI GRAVIDAE BREECH (Original) Prof Med Jour 17(2) 300-303 Apr, May, Jun 2010.

Manzoor Ahmed Faridi, Irbaz Bin Riaz, SPINAL ANAESTHESIA FOR CESAREAN DELIVERY; STUDY OF DIFFERENT DOSES OF IV EPHEDRINE AS PROPHYLAXIS TO PREVENT HYPOTENSION (Original) Prof Med Jour 17(4) 648-653 Oct, Nov, Dec 2010.

Habiba Sharaf Ali, Neelofer Saleem, Farah Agha. CAESAREAN SECTION; SURGICAL TECHNIQUES (Original) Prof Med Jour 17(3) 505-512 Jul, Aug, Sep 2010.

Robina Kausar, Lubna Yasmeen. ELECTIVE CAESAREAN SECTION; SHORT ANTIBIOTIC PROPHYLAXIS VERSUS PROLONGED ANTIBIOTIC THERAPY (Original) Prof Med Jour 17(2) 304-307 Apr, May, Jun 2010.

Samar Amin, Mahnaaz Roohi. CAESAREAN SECTION IN BIRTH PRESENTATION (Original) Prof Med Jour 9(1) 24-28 Jan, Feb, Mar 2002.

Samia Hassan, Misbah Kausar Javaid, Sadia Tariq. EMERGENCY CAESAREAN SECTION; COMPARATIVE ANALYSIS OF PROBLEMS ENCOUNTERED BETWEEN PATIENTS OF ELECTIVE CAESAREAN SECTION AND PATIENT FOR WHOM ELECTIVE CAESAREAN SECTION WAS PLANNED BUT ENDED UP IN EMERGENCY (Original) Prof Med Jour 15(2) 211215 Apr, May, Jun 2008.

Sunbal Kashif, Malahat Mansoor, Rubina Tariq, Tayyaba Tahira. VAGINAL BIRTH AFTER CAESAREAN SECTION; TO EVALUATE FACTORS FOR SUCCESSFUL OUTCOME (Original) Prof Med Jour 17(4) 665-669 Oct, Nov, Dec 2010.

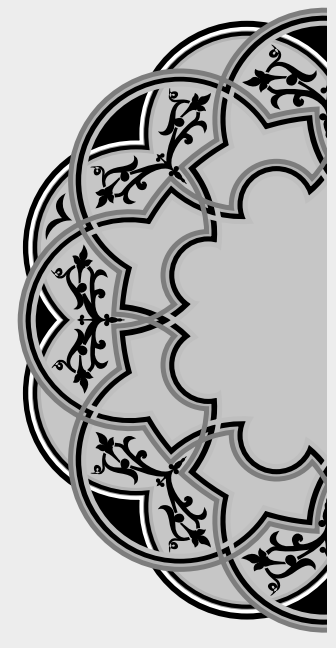

\section{"People too weak to follow their own dreams will always find a way to discourage your."}

Unknown

\section{AUTHORSHIP AND CONTRIBUTION DECLARATION}

\begin{tabular}{c|l}
\hline Sr. \# & \multicolumn{1}{|c}{ Author-s Full Name } \\
\hline 1 & Dr. Meshwari Beesham \\
2 & Dr. Pushpa Chetandas \\
3 & Dr. Neeta Sham
\end{tabular}

Sr. \# Author-s Full Name

3r. Neeta Sham
Contribution to the paper

Literature search performa formation, data collection \& data analysis

Data collection, literature search

Study concept literature search
Author $=\mathbf{s}$ Signature

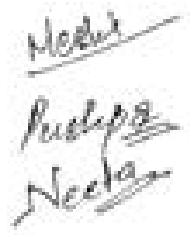

